\title{
SIMULATING AIR TEMPERATURE IN AN URBAN STREET CANYON IN ALL WEATHER CONDITIONS USING MEASURED DATA AT A REFERENCE METEOROLOGICAL STATION
}

\author{
E. ERELL ${ }^{\mathrm{a}, *}$ and T. WILLIAMSON ${ }^{\mathrm{b}}$ \\ a J. Blaustein Institutes for Desert Research, Ben-Gurion University of the Negev, 84990 Midreshet Ben-Gurion, Israel \\ ${ }^{\mathrm{b}}$ School of Architecture, Landscape Architecture and Urban Planning, The University of Adelaide, Adelaide 5005, Australia
}

Received 6 November 2005

Revised 12 February 2006

Accepted 15 February 2006

\begin{abstract}
A model is proposed that adapts data from a standard meteorological station to provide realistic site-specific air temperature in a city street exposed to the same meso-scale environment. In addition to a rudimentary description of the two sites, the canyon air temperature (CAT) model requires only inputs measured at standard weather stations; yet it is capable of accurately predicting the evolution of air temperature in all weather conditions for extended periods. It simulates the effect of urban geometry on radiant exchange; the effect of moisture availability on latent heat flux; energy stored in the ground and in building surfaces; air flow in the street based on wind above roof height; and the sensible heat flux from individual surfaces and from the street canyon as a whole. The CAT model has been tested on field data measured in a monitoring program carried out in Adelaide, Australia, in 2000-2001. After calibrating the model, predicted air temperature correlated well with measured data in all weather conditions over extended periods. The experimental validation provides additional evidence in support of a number of parameterisation schemes incorporated in the model to account for sensible heat and storage flux. Copyright (c) 2006 Royal Meteorological Society.
\end{abstract}

KEY WORDS: climate modelling; microclimate; urban canyon; weather stations

\section{INTRODUCTION}

In a comprehensive review of urban climate simulation models, Bornstein (1984) noted that a '. . potentially important use of such models could be in planning of urban development so as to create urban climates that are more healthy for urban dwellers.' Indeed, Clarke (1993) identified microclimate and site-specific data as one of the problem areas defining boundary conditions for building performance simulations. Despite this imperative, few, if any, comprehensive urban climate simulation models exist that focus directly on issues of importance for building thermal performance simulation. While a variety of research has led to models of the urban microclimate, Mills (1999) has noted that the gap between climatologists and urban planners was still large, so that application of climatology in planning was still very limited.

A case in point concerns the data required as input to building thermal software used to design heating, ventilation and air conditioning systems (HVAC) and to predict the energy performance of buildings. Knowledge of site-specific conditions is essential for the development of an architectural design that responds to the local environment and for accurate design of HVAC systems. Many building thermal performance/energy consumption simulation software packages come with inbuilt climate data files (usually 12 months data of hourly records) compiled from stations typically located at sites such as airports, which are implicitly assumed to be representative of the entire region. However, evidence of urban modification to weather indicates that

\footnotetext{
* Correspondence to: E. Erell, J. Blaustein Institutes for Desert Research, Ben-Gurion University of the Negev, 84990 Midreshet Ben-Gurion, Israel; e-mail: erell@bgumail.bgu.ac.il
} 
the differences between city-centre locations and the sites used by meteorological services are often quite substantial.

Many early models of the urban microclimate sought to simulate the three-dimensional structure of cities (Terjung and O'Rourke, 1980a; Terjung and O'Rourke, 1980b). However, in spite of vastly increased computing power, subsequent computer models have found it more useful to simulate what is considered by many to be the basic unit of the built environment - the so-called urban canyon. This allowed the basic processes to be studied separately, including short-wave radiation (Verseghy and Munro, 1989); long wave radiation (Arnfield, 1982); the surface energy balance (Arnfield et al., 1988; Arnfield, 1990, 2000; Sakakibara, 1996); and canyon air flow (Yamartino and Wiegand, 1986; Hunter et al., 1990, 1991; Macdonald, 2000). The evolution of air temperature in an urban canyon was modelled in a series of papers based on the concept of the cluster thermal time constant (CTTC), which expresses the thermal inertia of the urban physical structure (Swaid and Hoffman, 1990a; 1990b; 1990c; Swaid, 1993).

Modelling of the urban environment has also been carried out within a CFD framework (Bruse and Fleer, 1998; Chan et al., 2001; Chan et al., 2003; Dimoudi and Nikolopoulou, 2003; Takahashi et al., 2004; Xie et al., 2005), although this tool is usually applied to environments of a more limited physical scale. The main difficulty that must be overcome is the description of boundary conditions, which in a complex urban setting are often not known with sufficient accuracy. Unlike most analytical methods, CFD requires that all relevant fluxes be calculated at the appropriate scale in a full three-dimensional grid. In addition to requiring very detailed input, calculations require extensive computing resources, meaning models must be limited in space or simplified substantially.

While CFD modelling can typically deal with environments having a limited spatial scale, analytical mesoscale climate models can describe much larger areas, on the order of several kilometres, but in order to do so sacrifice the resolution required to describe conditions inside the urban canopy. Even models that distinguish between different building surfaces, such as roofs and walls, do so primarily to improve the accuracy of modelling exchanges in the boundary layer above building height (Masson, 2000; Martilli et al., 2002).

In the traditional approach to numerical modelling of the micro-climatic characteristics of the urban canopy layer, such as URMICLEM (Taha, 1978), weather data are used to provide geographically adjusted initial and boundary conditions to a planetary boundary layer (PBL) model. The meso-scale meteorological conditions predicted by such a model, in conjunction with detailed site-specific descriptors, are used to drive a canopy layer model capable of providing micro-scale temperatures at the site under consideration. This approach is based on a complete analysis of the energy fluxes, but requires detailed climatic information that is generally not available in typical weather stations. Furthermore, the meso-scale models require a description of the surface characteristics of grid elements representing a large urban area - information that is currently available in very few cities.

The objective of the research reported here was to investigate whether a simplified analytical model of the urban canyon can provide estimates of air temperature that are substantial improvements over the trivial case of using unprocessed data from a reference weather station for extended periods (such as a climate data file) and in all weather conditions.

\section{MODEL}

The CAT model is designed to calculate a representative air temperature in an urban canyon on the basis of measured meteorological parameters from a reference station located at a nearby site exposed to the same meso-scale climatic conditions. The underlying assumption is that in the absence of differences between the sites, such as in their morphology or surface cover, micro-climatic conditions in both sites would have been identical. It should be emphasised that the utility of the model depends on the availability of such reference data. Therefore, model inputs are limited to meteorological parameters monitored routinely at standard stations. This restriction has important implications that will be discussed in detail in the relevant sections. 
To keep the model simple, all the fluxes are accumulated on the assumption that the air is well mixed in the canyon: the air temperature throughout the street canyon is taken to be spatially uniform at any given time. This may not always be the case, especially in the presence of strong asymmetry in the solar flux on different canyon surfaces. However, the error resulting from this simplification is deemed relatively small: Nakamura and Oke (1988) found that except within about 0.5 metres of the floor or walls, the differences in air temperature are generally less than $1^{\circ} \mathrm{C}$. Measurement of air temperature carried out in this study at several points in each of the two street canyons (Section 3) confirmed these findings.

\subsection{Concept}

An energy balance is calculated from meteorological time series for the reference site and for each surface of the urban canyon, taking into account modifications to the energy exchange processes resulting from the specific characteristics of both sites. The micro-scale modification of air temperature at the reference site is calculated as the product of the sensible heat flux at the surface and a coefficient describing the resistance to turbulent heat transfer. This coefficient is derived from the surface heat exchange coefficient, modified by an empirical factor accounting for atmospheric stability and mechanical turbulence above the surface, normalised by the ratio of overall surface area of the site to its plan area. The time-dependent contribution of the local sensible heat flux to the air temperature at the reference site is then deducted from air temperature measured in a standard instrument screen to give $T_{\mathrm{b}}$, the meso-scale base temperature. The same methodology is then used to calculate the ensemble contribution to the local canyon air temperature of sensible heat flux from all canyon surfaces, similarly modified by the resistance of the urban canyon site to turbulent heat transfer. This contribution is then added to the base temperature to give the predicted air temperature in the canyon.

The CAT model evolved from the modified CTTC analytical model (Elnahas and Williamson, 1997), that incorporated a cluster thermal time constant for predicting air temperature variations in the urban canopy layer. An extended version of a previous model originally proposed by Swaid and Hoffman (1990c), this model predicted air temperature at an urban location based on measured temperature at a rural reference site, modified by the contribution of characteristically urban conditions. The conceptual basis for this conversion was stated by Elnahas and Williamson (1997) as follows:

$$
\begin{aligned}
T_{\mathrm{a}}(t)_{\mathrm{urb}} & =T_{\mathrm{b}}+\Delta T_{\mathrm{sol}}(t)_{\mathrm{urb}}-\Delta T_{\mathrm{lw}}(t)_{\mathrm{urb}} \\
T_{\mathrm{a}}(t)_{\mathrm{met}} & =T_{\mathrm{b}}+\Delta T_{\mathrm{sol}}(t)_{\mathrm{met}}-\Delta T_{\mathrm{lw}}(t)_{\mathrm{met}}
\end{aligned}
$$

where $T_{\mathrm{a}}(t)$ refers to air temperature at a given location, $T_{\mathrm{b}}$ the meso-scale base temperature, and $\Delta T_{\text {sol }}$ and $\Delta T_{\mathrm{lw}}$ the net short wave and long-wave radiative contribution to the local temperature. The subscripts ' urb' and 'met' refer to urban and meteorological (reference) locations, respectively. Combining the above expressions yields:

$$
T_{\mathrm{a}}(t)_{\mathrm{urb}}=T_{\mathrm{a}}(t)_{\mathrm{met}}+\left(\Delta T_{\mathrm{sol}}(t)_{\mathrm{urb}}-\Delta T_{\mathrm{sol}}(t)_{\mathrm{met}}\right)-\left(\Delta T_{\mathrm{lw}}(t)_{\mathrm{urb}}-\Delta T_{\mathrm{lw}}(t)_{\mathrm{met}}\right)
$$

The above procedure attributes the variation in air temperature to differences in short wave and long wave energy balances between the urban site and the meteorological (reference) site. However, the same method may be employed to express differences resulting from other modifiers of local micro-climatic conditions, such as, for example, anthropogenic heat, the hydrological balance or the effects of vegetation, which may affect latent heat.

Inputs required by the model comprise two separate categories:

- Time series describing meteorological conditions at the reference site, including the dry bulb temperature of the air, relative humidity, wind speed, global and diffuse solar radiation on a horizontal plane, and cloud cover.

- Site characteristics describing both the reference site and the urban site being simulated, including geographic location (latitude and longitude); building geometry, including street canyon aspect ratio, 
building density and ratio of massive external walls to site area; material properties, including surface albedo and the coefficients of the objective hysteresis model (OHM) of thermal storage (Grimmond et al., 1991); hydrological factors affecting the parcelling of turbulent heat flux into latent heat and sensible heat, including the coefficients of the LUMPS model by Grimmond and Oke (2002).

The geometric representation of the urban environment is two-and-a-half-dimensional: canyon dimensions are given only in cross-section (length in the direction of the main longitudinal axis is considered semiinfinite). However, treatment of in-canyon wind is fully three-dimensional, as is the incorporation of solar position in the computation of short-wave radiant exchange.

The model treats each of the following factor components of the heat balance as follows:

\subsection{Radiative exchanges}

Net radiation $\left(Q^{*}\right)$ may be measured directly, but is not usually monitored in a standard meteorological station. Furthermore, net radiant exchange depends on the orientation of the relevant surface, its angle of tilt with respect to the horizon and its degree of exposure to direct solar radiation, to the sky and to other terrestrial surfaces. The CAT model therefore utilises more commonly available data - global solar radiation and diffuse solar radiation (both on an unobstructed horizontal surface), and cloud cover, all recorded at the reference station. Net radiant exchange at the reference station and on each surface in the urban canyon is then calculated on the basis of solar geometry and the respective view factors of the participating surfaces.

Incoming direct normal (beam) solar radiation is calculated from measured global radiation and diffuse radiation, taking into account solar elevation. Beam radiation is then used to calculate the direct component on building surfaces, with respect to orientation and mutual shading by other canyon surfaces. The proportion of each surface exposed to direct radiation is calculated using a model that allows input of separate (different) values for each canyon wall. In addition, the height and setback of adjacent buildings may be input to account for obstructions created by buildings that are much taller than those forming the primary canyon perimeter, or for tower blocks constructed on a 'podium' that comprises the actual canyon walls. Canyon surfaces not exposed to direct solar radiation, including portions of exposed surfaces shaded by adjacent walls, are considered as being illuminated by diffuse radiation and by reflected radiation only, in proportion to the respective view factors for each of the source areas.

The time-dependent total solar radiant flux on the $i_{\text {th }}$ canyon surface receiving direct solar radiation as well as reflected radiation from $j$ other canyon surfaces is thus given by the following expression:

$$
I_{(\mathrm{t})}=I_{\operatorname{dir}(\mathrm{t})}(1-P S A(\mathrm{t}))+I_{\operatorname{dif}(\mathrm{t})} \Psi_{\mathrm{s}}+\sum_{\mathrm{j}} I_{\operatorname{dir}+\operatorname{dif}(t)} j\left(1-m_{\mathrm{j}}\right)\left(\Psi_{\mathrm{i}-\mathrm{j}}\right)
$$

where $I_{(\mathrm{t})}$ is the mean hourly total solar radiation incident on the surface $\left(\mathrm{W} \mathrm{m}^{-2}\right)$, PSA is the partial shaded fraction of the surface, $I_{\operatorname{dir}(\mathrm{t})}$ the hourly mean unobstructed direct component of the solar radiation, $I_{\mathrm{dif}(\mathrm{t})}$ the hourly mean unobstructed diffuse component of the solar radiation, $I_{\operatorname{dir}+\operatorname{dif}(\mathrm{t})}$ the combined direct and diffuse components of the solar radiation, $\Psi$ the view factor between two surfaces, $m_{\mathrm{j}}$ the solar absorptivity of surface $j\left(\mathrm{~W} \mathrm{~m}^{-2^{\circ}} \mathrm{K}\right)$ and $\Psi_{\mathrm{s}}$ the mean sky view factor for a surface. Reflected radiation, as noted above, takes into account primary reflections only.

Incoming long wave radiation ( $\mathrm{L} \downarrow)$ is calculated from the dry bulb temperature of the air and from atmospheric humidity for clear sky conditions via the empirical correlation proposed by Brutsaert (1982) for atmospheric emissivity,

$$
\varepsilon_{\mathrm{a}}=1.24\left(e_{\mathrm{a}} / T_{\mathrm{a}}\right)^{\frac{1}{7}}
$$

where $e_{\mathrm{a}}$ is the partial water vapour pressure of air $(\mathrm{mb})$ and $T_{\mathrm{a}}$ air temperature $(\mathrm{K})$. The partial water vapour pressure of air may be calculated from relative humidity and air temperature following the procedure set out in (ASHRAE, 1989). 
Sky radiation is calculated using the Stefan-Boltzmann relationship

$$
L \downarrow=\sigma \varepsilon_{\mathrm{a}} T_{\mathrm{a}}^{4}
$$

where $\sigma$ is the Stefan-Boltzmann constant $\left(5.67 \times 10^{-8} \mathrm{~W} \mathrm{~m}^{-2} \mathrm{~K}^{-4}\right), \varepsilon_{\mathrm{a}}$ is sky emissivity and $T_{\mathrm{a}}$ air temperature $(\mathrm{K})$.

A correction factor incorporating the effect of clouds on $\mathrm{L} \downarrow$ is applied following Martin (1989):

$$
L \downarrow(n)=\left(1+0.0224 n-0.0035 n^{2}+0.00028 n^{3}\right) L \downarrow_{\text {clear }}
$$

Compared with other empirical corrections for the effect of clouds, such as the one proposed by Oke (1987), this expression sacrifices accuracy for simplicity of application: it requires no information on cloud type, which may not always be available in standard meteorological records.

The approach adopted in the CAT model for calculating outgoing long wave radiation is a compromise between detailed modelling of surface temperature and the use of ambient air temperature as a surrogate for it. The former is accurate, but requires a detailed description of the (time-changing) thermal properties of the solid, whereas the latter is simple but less accurate. Surface temperature is approximated by the 'sol-air temperature', which is defined as 'the equivalent outdoor temperature which will cause the same rate of heat flow at the surface and the same temperature distribution throughout the material as results from the outdoor air temperature and the net radiation exchange between the surface and its environment' (Rao and Ballantyne, 1970), and is calculated as follows (the commonly used notation has been modified to conform to conventions used in climatology):

$$
T_{\mathrm{sol}}=T_{\mathrm{a}}+\frac{K \downarrow \alpha+\varepsilon_{\mathrm{s}} L^{*}}{h_{\mathrm{c}}}
$$

where $T_{\text {sol }}$ is given in $K, K \downarrow$ is incoming short-wave radiation ( $\mathrm{W} \mathrm{m}^{-2}$ ), $\alpha$ is short-wave absorptivity of the surface, $\varepsilon_{\mathrm{s}}$ is the long wave emissivity of the surface, $L^{*}$ is net long wave radiation at the surface ( $\mathrm{W} \mathrm{m}^{-2}$ ) and $h_{\mathrm{c}}$ the surface convective heat exchange coefficient. The outgoing long wave radiation $(L \uparrow)$ is itself a function of the sol-air temperature, so its value is obtained by iterative calculation of the expression above until $T_{\text {sol }}$ is obtained to an accuracy of less than $0.5 \mathrm{~K}$. The contributions of the ground surface and vertical surfaces of the canyon are calculated separately taking into account their respective view factors to the sky.

\subsection{Heat storage $\left(\Delta \mathrm{Q}_{s}\right)$}

Heat storage is modelled using the Camuffo and Bernardi (1982) formulation:

$$
\Delta Q_{\mathrm{s}}=a_{1} Q^{*}+a_{2} \frac{\partial Q^{*}}{\partial t}+a_{3}
$$

where $t$ is time; parameter $a_{1}$ indicates the overall strength of the dependence of the storage heat flux on net radiation; $a_{2}$ determines whether the curves $\Delta Q_{\mathrm{S}}$ and $Q^{*}$ are exactly in phase $\left(a_{2}=0\right)$, or $\Delta Q_{\mathrm{S}}$ precedes $Q^{*}\left(a_{2}>0\right)$; and $a_{3}$ is the size of $\Delta \mathrm{Q}_{\mathrm{S}}$ when $Q^{*}$ becomes negative (positive values indicates $\Delta \mathrm{Q}_{\mathrm{S}}$ becomes negative before $Q^{*}$ ). The values of coefficients $a_{1}, a_{2}$ and $a_{3}$ correspond to typical values proposed by Grimmond and Oke (2002).

\subsection{Turbulent heat flux $\left(\mathrm{Q}_{H}\right.$ and $\left.\mathrm{Q}_{E}\right)$}

The value of $h_{\mathrm{c}}$, the surface heat exchange coefficient, is affected by the relative temperatures of the surface and the adjacent air layer, by the orientation of the surface with respect to the horizontal, and most importantly, by the speed of air movement across the surface. Since $h_{\mathrm{c}}$ cannot be determined by analytical 
methods, CAT employs empirical correlations for horizontal and vertical surfaces, obtained experimentally on building surfaces at an urban site (Hagishima and Tanimoto, 2003):

$$
h_{\mathrm{c}(\mathrm{hor})}=3.96 \sqrt{\overline{u^{2}+v^{2}+w^{2}}}+6.42, h_{\mathrm{c}(\mathrm{vert})}=10.2 \sqrt{\overline{u^{2}+v^{2}+w^{2}}}+4.47
$$

where $u, v$ and $w$ are wind vectors $\left(\mathrm{m} \mathrm{s}^{-1}\right)$ and $h_{\mathrm{c}}$ is given in $\mathrm{W} \mathrm{m}^{-2} \mathrm{~K}^{-1}$.

In the reference site, wind speed near the surface $(20 \mathrm{~cm}$ height $)$ is derived from data measured at $10 \mathrm{~m}$ height assuming a standard logarithmic profile. Values for the zero-plane displacement $(d)$ and the roughness length $\left(z_{0}\right)$ are estimated in accordance with the aerodynamic characteristics of the reference site. In the case of a typical meteorological station, $d$ is on the order of a few millimetres and $z_{0}$ about $1 \mathrm{~cm} . u_{*}$ can then be calculated using a value of $k=0.4$ for the von Karman constant:

$$
u_{*}=k \times \frac{v_{\mathrm{z}}}{\ln \left(z-d / z_{0}\right)}
$$

Using the resulting value for $u_{*}$, the expression is then solved for $v_{\mathrm{z}}$ to yield wind speed near the surface.

The simple logarithmic profile is not appropriate in the urban canyon. Wind speed near canyon surfaces is calculated on the assumption that a vortex is formed, using the Hotchkiss and Harlow (1973) model, quoted in Yamartino and Wiegand (1986), to calculate wind speed near each of the surfaces from wind speed above the canyon top. The transverse (horizontal) component of the flow $(u)$ and the vertical component $(w)$ at any point in a two-dimensional rectangular notch of depth $H$ and width $B$ (in effect - an urban canyon) are given by the following expressions:

$$
\begin{aligned}
u & =u_{0}(1-\beta)^{-1}[\gamma(1+k y)-\beta(1-k y) / \gamma] \sin (k x) \\
w & =-u_{0} k y(1-\beta)^{-1}[\gamma-\beta / \gamma] \cos (k x)
\end{aligned}
$$

where $k=\pi / B: \beta=\exp (-2 \mathrm{kH}) ; \gamma=\exp (\mathrm{ky}) ; y=z-H$; and $u_{0}$ is the transverse wind speed above the canyon (at the point $x=\mathrm{B} / 2, z=\mathrm{H}$ ).

The transverse flow, which is independent of the along-canyon longitudinal flow, has a logarithmic profile:

$$
v(z)=v_{\mathrm{r}} \log \left[\frac{z+z_{0}}{z_{0}}\right] / \log \left[\frac{z_{\mathrm{r}}+z_{0}}{z_{0}}\right]
$$

where $v_{\mathrm{r}}$ is the along-canyon component of the wind speed at reference height $\mathrm{r}$ above the canyon and $z_{0}$ is the roughness length.

The roughness length of a surface depends on the height of individual roughness elements, their geometry and their spacing. The numerous attempts to obtain representative values of the roughness length for various surfaces have been reviewed by Wieringa (1993), Bottema (1997) and Grimmond et al. (1998). However, the complexity and heterogeneity of the urban surface have made it very difficult to assign a single value for all cities, and none of the models proposed so far has been able to explain more than $24 \%$ of the variance in the measured data (Grimmond and Oke, 1999a). Grimmond and Oke suggest that the roughness length of an urban area is related to urban density, measured by an index such as the frontal area index or the plan area index. However, in the absence of accurate local measurements of the characteristic wind field, the roughness length is estimated as being 1/10 the average height of the canyon walls, following the recommendation of Grimmond et al. (1998).

Sensible heat flux is parameterised for each canyon surface from the net radiant balance $\left(Q^{*}\right)$ and the storage flux $\left(\Delta Q_{\mathrm{s}}\right)$ (De Bruin and Holtslag (1982), in the revised form given by Grimmond and Oke (2002) for urban conditions):

$$
Q_{\mathrm{H}}=\frac{(1-\alpha)+(\gamma / s)}{1+(\gamma / s)}\left(Q^{*}-\Delta Q_{\mathrm{s}}\right)-\beta
$$


where $s$ is the slope of the saturation vapour pressure-versus-temperature curve; $\gamma$ is the psychrometric constant; and $\alpha$ and $\beta$ are empirical parameters. $\alpha$ depends on the soil moisture status, and accounts for the strong correlation of $Q_{\mathrm{H}}$ and $Q_{\mathrm{E}}$ with $Q^{*}-\Delta Q_{\mathrm{S}}$, whereas $\beta$ accounts for the uncorrelated portion.

\subsection{Anthropogenic heat $\left(\mathrm{Q}_{F}\right)$}

In the CAT model, anthropogenic heat flux $Q_{\mathrm{F}}$ is added to the sensible heat flux $Q_{\mathrm{H}}$ before the temperature modification procedure is carried out. The energy is treated as if it is released from a point source in the centre of the canyon. Monthly mean values of total anthropogenic heat flux density as a base are converted by a factor related to the time of day to account for the typical diurnal pattern of energy consumption (Sailor and $\mathrm{Lu}, 2004)$.

\subsection{Temperature prediction from sensible heat flux}

The local effect of the sensible heat flux at the surface on air temperature in the canopy layer depends on the exchange of energy with the mixed layer above roof level, and is affected by two classes of factors (Kastner-Klein and Plate, 1999):

- The geometry of the urban canyon, especially its aspect ratio; and the morphology of the buildings it is defined by. For a given canyon, the effect of these factors may be considered fixed over time.

- The characteristics of the airflow above the roofs, in particular wind speed and direction with respect to the canyon axis, and the magnitude of the turbulence. A further factor is the state of atmospheric stability near the surface. The effect of these factors changes constantly.

Atmospheric stability, typically represented by the Richardson number, cannot usually be calculated from data measured at a typical weather station. An alternative method of accounting for the effects of atmospheric stability and mechanical mixing on turbulent flux was incorporated in CAT, whereby four separate classes of flow regimes were defined on the basis of the temperature difference between the sol-air temperature of the ground surface and the dry bulb temperature of the air at screen level. This temperature difference is a useful proxy for stability, since calculation of the sol-air temperature incorporates, in addition to air temperature, the meteorological factors that affect stability, namely radiant exchange (including the effects of cloud cover and air moisture content) and wind. Thus, the sol-air temperature can only be substantially below air temperature on clear nights with little or no wind; and it can only be much greater than the air temperature when the surface is exposed to intense solar radiation, if wind is light. Table I describes four classes of mixing regimes, using the sol-air temperature as an indicator of the combined effect of mechanical mixing and buoyancy flows, as described above.

Each of the mixing regimes is characterised by a coefficient of turbulent exchange between the canyon and the mixed layer above roof height. This coefficient, designated $m$, may range in value between zero, corresponding to no mixing at all, and unity, corresponding to perfect mixing. The actual values used in the simulation were assigned empirically (Section 4)

Table I. Definition of mixing regimes between canopy layer and mixed layer

\begin{tabular}{lc}
\hline Mixing regime & $\begin{array}{c}\text { Surface temperature } \\
\text { depression }(K)\end{array}$ \\
\hline Negligible mixing & $<-2$ \\
Light mixing & $-2<\Delta T<0$ \\
Moderate mixing & $0<\Delta \mathrm{T}<5$ \\
Vigorous mixing & $5<\Delta \mathrm{T}$ \\
\hline
\end{tabular}


The exchange of sensible heat between the surface and the mixed layer above rooftop height can be expressed by means of a bulk aerodynamic formulation for fluxes, of the general form:

$$
Q_{\mathrm{H}}=\Delta T / r
$$

where $Q_{\mathrm{H}}$ is the sensible heat flux, obtained from the sum of the contributions of the individual surfaces comprising the envelope of the site, weighted by their respective areas as a proportion of the overall plan area of the site; $\Delta T$ is the temperature difference between the screen air temperature and the base temperature in the reference layer, which will vary over time; and $r$ is a resistance to sensible heat exchange.

The value of $r$ is given by the following expression:

$$
r=(1-m) * r_{\text {surf }}
$$

where $r_{\text {surf }}$ is the resistance to sensible heat transfer at the surface and $m$ is the coefficient of turbulent exchange.

The resistance to convective sensible heat transfer between canyon surfaces and the air $\left(r_{\text {surf }}\right)$ is expressed as the inverse of $h_{\mathrm{c}}$, the surface heat transfer coefficient in Equation 10 above, normalised by the ratio of the total surface area of the site to its plan area $(\chi)$ :

$$
r_{\text {surf }}=\frac{1}{h_{\mathrm{c}} \times \chi}
$$

Normalisation by $\chi$ is necessary because the increased surface area of the urban site results in more efficient heat transfer between the solid storage mass and the canopy layer air: The city, in its conceptual form as a series of urban canyons, in effect acts as a giant ribbed heat exchanger. Thus, the value of $r_{\text {surf }}$ is lower for deep canyons than for shallow ones. In the event of a perfectly flat site, $\chi$ equals unity and Equation 18 collapses into the familiar relationship where resistance is simply the inverse of conductance. The higher efficiency of heat transfer resulting from the increased surface area of urban sites is offset to a certain degree by the reduction in the magnitude of the surface convective coefficient, $h_{\mathrm{c}}$, since wind speed near the surface of a street canyon is generally lower than in open sites.

The expression $(1-m)$ accounts for differences in the rate of turbulent exchange at the canyon top due to mechanical mixing and thermal buoyancy. If either mechanism results in vigorous mixing of the air, $m$ has a value approaching unity, $(1-m)$ approaches zero and the effective resistance of the canyon system to exchange of sensible heat with the mixed layer above becomes negligible. If there is little mixing of the air, typically during strong thermal inversions, $m$ has a much smaller value, $(1-m)$ is proportionately larger and the product $r_{\text {surf }} \times(1-m)$ approaches the value of $r_{\text {surf }}$. In this case, sensible heat exchange is limited to a shallow layer of air near the surface.

Finally, the time-varying change in air temperature resulting from the local characteristics of the reference site and of the urban canyon, $\Delta T a(t)_{\text {met }}$ and $\Delta T a(t)_{\text {urb }}$ respectively, is obtained by solving Equation 16 for $\Delta T$ separately for each of the two sites. The air temperature in the urban canyon $T a(t)$ urb is then calculated as the sum of the air temperature at the reference station $T a(t)_{\text {met }}$ and the net change in temperature between the two sites:

$$
T_{\mathrm{a}}(t)_{\mathrm{urb}}=T_{\mathrm{a}}(t)_{\mathrm{met}}+\left(\Delta T_{\mathrm{a}}(t)_{\mathrm{urb}}-\Delta T_{\mathrm{a}}(t)_{\mathrm{met}}\right)
$$

The CAT model has been implemented in Fortran language computer code to operate in a Windows environment.

\section{FIELD DATA}

Detailed micro-meteorological data were monitored for an extended period of nearly a year at two urban canyons in central Adelaide, Australia, and at a reference site about $1.6 \mathrm{~km}$ to the northeast, representing rural 
conditions (Figure 1). Weather records for the same period were also provided by the Bureau of Meteorology (BoM) from the Kent Town station, about $1.7 \mathrm{~km}$ east of the urban sites. All sites are assumed to be affected by common meso-scale environmental conditions. The analysis in the present paper is based on data from just one of the two urban street canyons monitored, and uses the Kent Town BoM data as the reference. A comparison of the two urban sites and the two reference sites is presented in a separate publication (Erell and Williamson, 2006).

The study area is in the core of the Adelaide metropolitan area, which extends about $20 \mathrm{~km}$ east from the Gulf of St Vincent to the Adelaide Hills and about $25 \mathrm{~km}$ from north to south, and which has a total population of close to a million residents. Adelaide has a Mediterranean climate with hot summers (February mean temperature $23^{\circ} \mathrm{C}$ ), mild winters (July mean $12^{\circ} \mathrm{C}$ ), and an average annual rainfall of about $550 \mathrm{~mm}$. The elevation of the city centre is about $50 \mathrm{~m}$ above sea level.

Data representative of the whole of the study area included global solar radiation; diffuse solar radiation and net all-wave radiation. The reference station monitored site-specific dry bulb temperature, relative humidity, wind speed and direction, soil temperature and soil moisture. At the urban sites, measurements of air temperature were made at several points in each street cross-section in specially constructed instrument shields, shown in Figure 2 (Erell et al., 2005). (However, comparison of temperature records from up to five sensors in each street section later showed that differences among sensors were small and non-systematic. The average temperature from all sensors was used to represent the canyon temperature.) Relative humidity, wind speed and direction were measured at single point. A detailed description of the instrumentation, data processing and quality assurance procedures is given in Erell and Williamson (2006).

The urban sites were located in two adjacent alleys in the central business district: Chesser St, oriented approximately north-south, and French St, oriented at right angles to it, approximately east-west. The present study refers only to data from Chesser St (Figure 3). Measurements were taken about $30 \mathrm{~m}$ north and west of the intersection between them. Both alleys are approximately $6 \mathrm{~m}$ wide, fully paved with asphalt. Adjacent buildings are of varying heights, including two office towers of approximately 50-m height. However, the street canyon is formed primarily by lower structures - either a two-storey podium on which the office block is constructed at a setback of about $8 \mathrm{~m}$, or by two-three storey low-rise buildings. The mean canyon aspect ratio near the points of measurement is approximately 1.35 . The surfaces comprising the canyon walls are either of clay brick or brick veneer. Glazed openings comprise a relatively small proportion of the total surface area. French $\mathrm{St}$ is totally devoid of vegetation, while a sparse deciduous vine covers a 10-m section

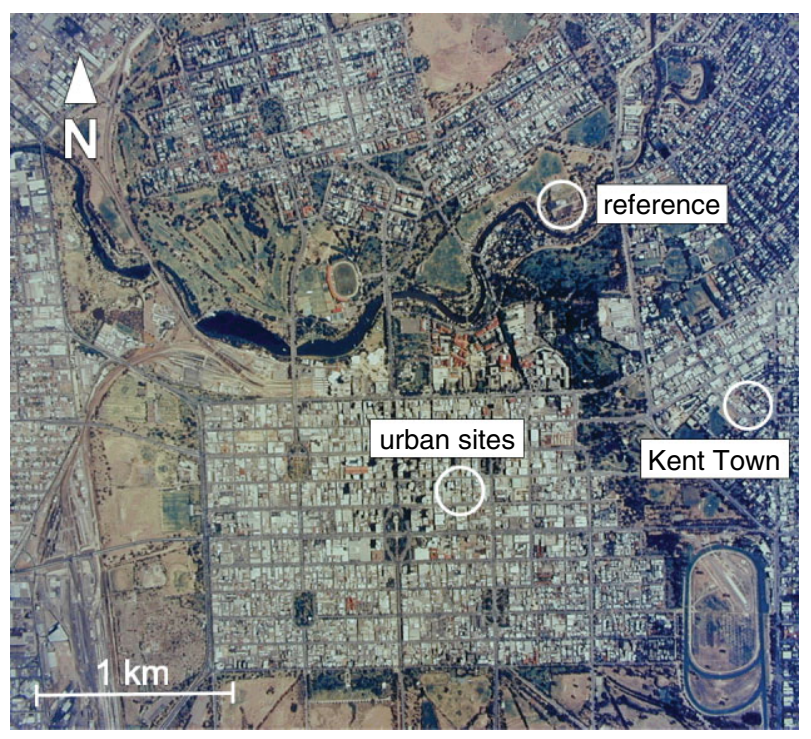

Figure 1. Aerial photograph of central Adelaide showing location of monitoring sites. This figure is available in colour online at www.interscience.wiley.com/ijoc 


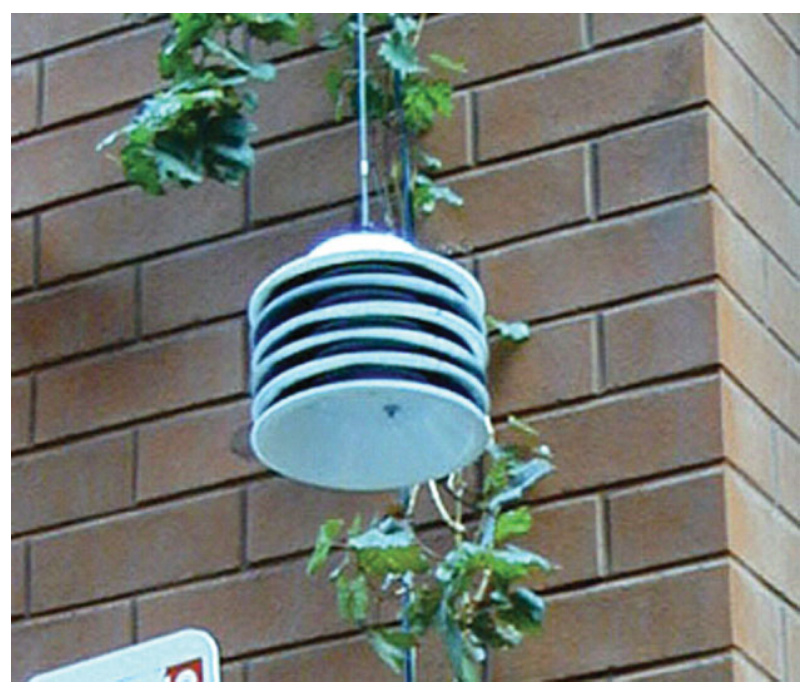

Figure 2. Instrument screen for temperature sensors. This figure is available in colour online at www.interscience.wiley.com/ijoc

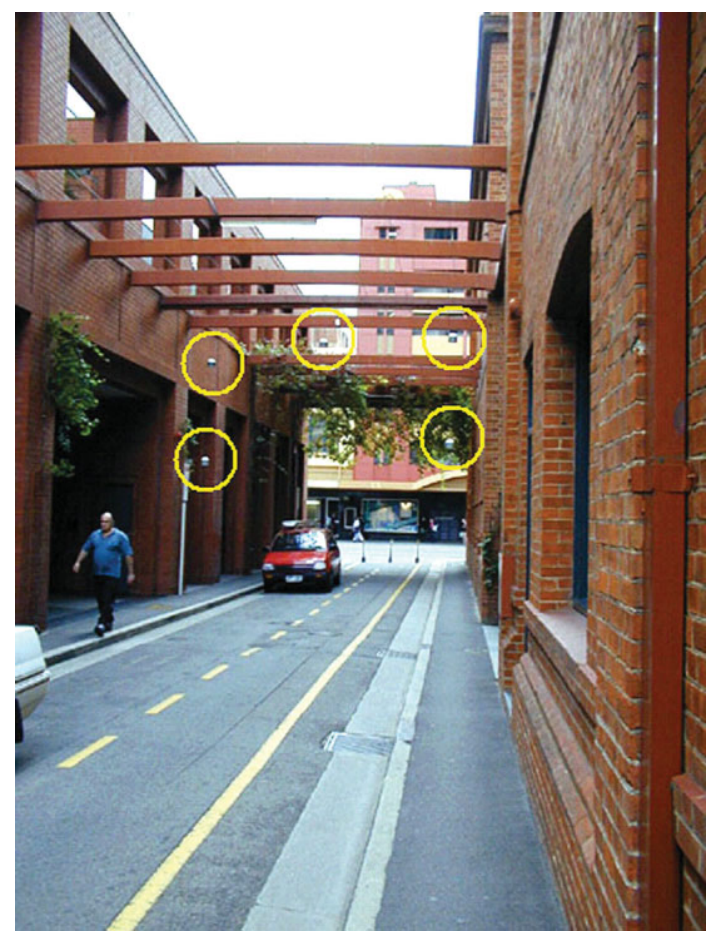

Figure 3. View of the Chesser St monitoring site, looking north. Circles show location of temperature sensors. Wind speed and direction were measured at the middle of the road, $6 \mathrm{~m}$ above street level, approximately above the position where this photograph was taken.

This figure is available in colour online at www.interscience.wiley.com/ijoc

of Chesser St north of the monitoring site. Vehicular traffic in both streets was very low: The total number of car trips on each street is estimated at no more than 20-30 per hour during office hours, and a negligible number at night and on weekends. The number of pedestrians is likewise very small. There appeared to be no local sources of heat, such as air conditioning systems (window units or compressors of central systems). 
Anthropogenic heat fluxes were therefore considered to be quite low, and due almost entirely to conduction through building envelopes.

The Kent Town BoM station is located in a suburban location about $200 \mathrm{~m}$ east of the belt of parklands surrounding central Adelaide (Figure 4). Adjacent buildings are mostly one-storey residential houses, and the total distance between facades on opposite sides of the street is nearly $15 \mathrm{~m}$. The resulting sky view factor of the station is 0.93 (Elnahas, 1996).

\section{MODEL CALIBRATION}

The monitoring program was too limited in scope to allow direct measurement of the fluxes that are parameterised within the CAT model. The methodology adopted to validate the model was therefore based on a two-stage approach: Approximate values for the various empirical parameters were introduced, based on published correlations. The model was then run on experimental data for a month-long period (June 2000), using Kent Town BoM meteorological time series as the input and mean air temperature measured in Chesser Street urban site as the object of the simulation. The initial values of the coefficients of the empirical mixing coefficient were then modified to minimise errors in the predicted temperature in the urban canyon for this period. No further modification was attempted at this stage for the coefficients of any of the other parameterisations.

Having calibrated the model, validation was carried out by statistical analysis of the time series of predicted air temperature and measured values during several other month-long periods (May and November 2000 and March 2001). Throughout this procedure, values of all empirical coefficients obtained earlier for the various parameterisation schemes were left unchanged.

\subsection{Calibration of the OHM model for ground storage}

The OHM model, which is based on previous work by Camuffo and Bernardi (1982) requires empirical constants to describe the typical hysteresis between net radiant exchange at the surface, which drives the process, and energy storage. Empirical values have been obtained by researchers for a variety of surfaces, but as Table II (Grimmond and Oke, 1999b) shows, there is still a considerable range for most materials.

Arnfield and Grimmond (1998) suggested that the values of these coefficients may vary over time as a function of various environmental factors, such as air temperature, wind speed and exposure to solar radiation.

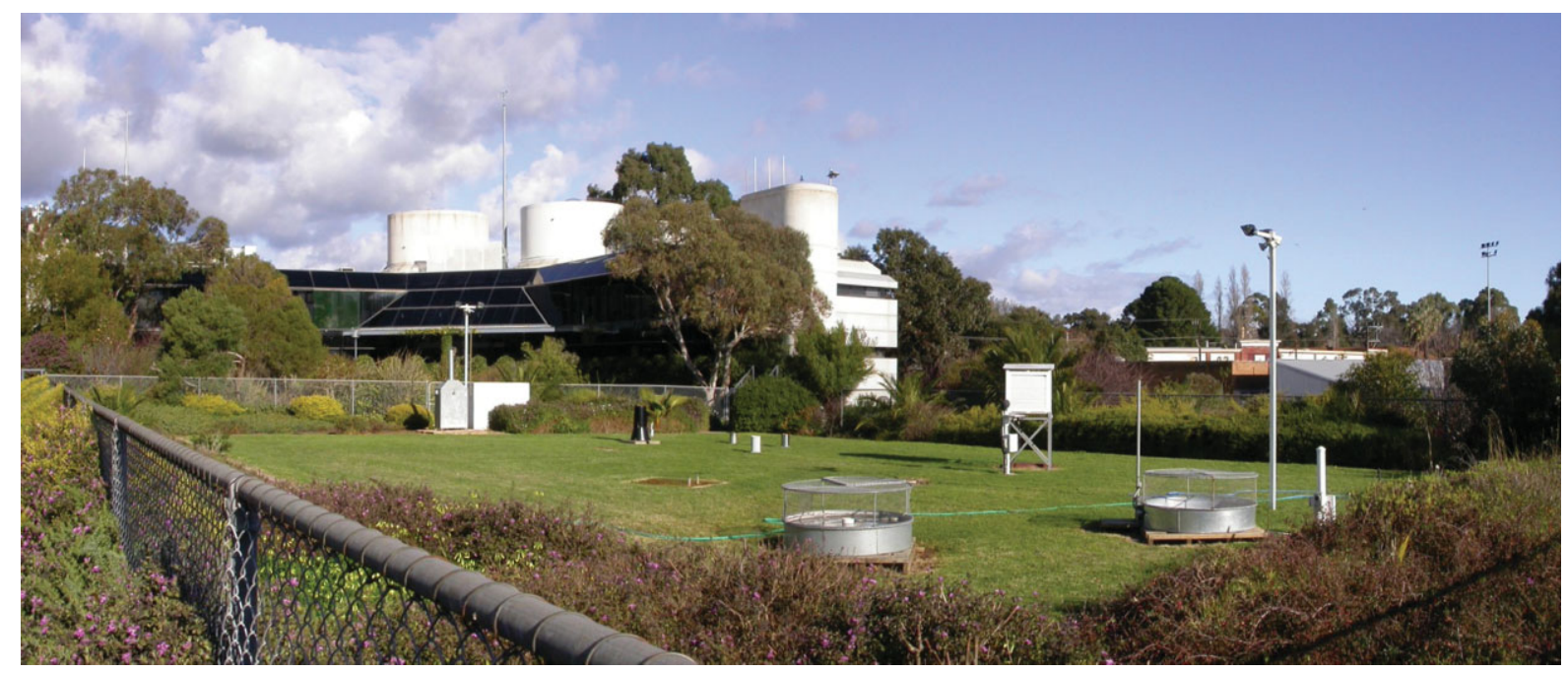

Figure 4. View of the Australian Bureau of Meteorology station at Kent Town. This figure is available in colour online at www.interscience.wiley.com/ijoc 
Table II. Coefficients of the OHM model for various surface types (Grimmond and Oke, 1999b)

\begin{tabular}{llccc}
\hline Surface cover type & Source & \multicolumn{3}{c}{ OHM coefficients } \\
\cline { 3 - 5 } & & $a_{1}$ & $\begin{array}{c}a_{2} \\
(h)\end{array}$ & $a_{3}$ \\
& & & & \\
\hline 1. Greenspace/open & & & \\
Mixed forest & McCaughey (1985) & 0.11 & 0.11 & -12.3 \\
Sort grass & Doll et al. (1985) & 0.32 & 0.54 & -27.4 \\
Bare soil & Novak (1981) & 0.38 & 0.56 & -27.3 \\
Bare soil - wet & Fuchs and Hadas (1972) & 0.33 & 0.07 & -34.9 \\
Bare soil - dry & Fuchs and Hadas (1972) & 0.35 & 0.43 & -36.5 \\
Soil & Asaeada and Ca (1993) & 0.36 & 0.27 & -42.4 \\
Water - shallow turbid & Souch et al. (1998) & 0.50 & 0.21 & -39.1 \\
2. Paved/impervious & & & & \\
Concrete & Doll et al. (1985) & 0.81 & 0.48 & -79.9 \\
Concrete & Asaeada and Ca (1993) & 0.85 & 0.32 & -28.5 \\
Asphalt & Narita et al. (1984) & 0.36 & 0.23 & -19.3 \\
Asphalt & Asaeada and Ca (1993) & 0.64 & 0.32 & -43.6 \\
Asphalt & Anandakumar (1998) & 0.82 & 0.68 & -20.1 \\
\hline & & & & \\
\hline
\end{tabular}

However, the basis for their hypothesis is a numerical procedure of back-calculating values to fit measured data from one canyon (Nunez and Oke, 1977), and no general relationships are provided that may be applied elsewhere.

Since there appear to be no universally accepted values for the surface types occurring in the stations monitored in Adelaide, average values for each surface type were calculated from the table above and used in the OHM model of storage flux as a first approximation (Table III).

The ground surface at the Kent Town BoM station was modelled using an average value for the two vegetated surface types in Table II. In the absence of specific data either for brick or for wall surfaces in general, all walls were modelled using average values of the two listings for concrete. The values for the asphalt road in Chesser Street are the average of the three entries for asphalt above. The values of all of these coefficients were considered as being constant over time and independent of environmental conditions.

\subsection{Calibration of the expression for sensible heat flux}

The parameterisation for sensible heat flux proposed by De Bruin and Holtslag (1982), in the revised form given by Grimmond and Oke for urban conditions, requires two empirical constants $(\alpha$ and $\beta$ ). Values for these constants depend upon the availability of moisture at the surface, which affects the parcelling of available energy into sensible and latent heat. Hanna and Chang (1992) list typical values of $\alpha$ and $\beta$ for

Table III. Coefficients of the OHM model for various surface types used in the CAT for Adelaide

\begin{tabular}{llccc}
\hline Location & Surface material & \multicolumn{3}{c}{ OHM coefficients } \\
\cline { 3 - 5 } & & $a_{1}$ & $\begin{array}{c}a_{2} \\
(h)\end{array}$ & $\begin{array}{c}a_{3} \\
\left(\mathrm{~W} \mathrm{~m} \mathrm{~m}^{-2}\right)\end{array}$ \\
& & & 0.33 & -20 \\
BoM ground & Grass, planting & 0.22 & 0.40 & -54 \\
BoM walls & Brick & 0.83 & 0.41 & -28 \\
Chesser road & Asphalt & 0.61 & 0.40 & -54 \\
Chesser walls & Brick & 0.83 & & \\
\hline
\end{tabular}


various landscape types (Table IV). However, more recent findings (Grimmond and Oke, 2002) suggest that these values are too high, especially for cities in dry climates or with little vegetation: The value of $\alpha$ was found to vary between 0.19 in Mexico City to 0.71 in Chicago, averaging about 0.45 in the cities studied, whereas the value for $\beta$ in urban sites was found to be in the range -0.3 to 8.4 , with an average of about 3 .

Parklands surround the city centre of Adelaide, but there is very little vegetation in the immediate vicinity of the urban monitoring sites. In the absence of substantial areas of exposed pervious soil where rainfall can be collected and later evaporated over extended periods, the appropriate value of the moisture availability index in this case was therefore likely to be in the range $0.2-0.3$, similar to the value reported for the downtown areas of Mexico City and Tucson (Grimmond and Oke, 2002). A constant value of 0.25 was therefore assigned to the urban sites, while the value of $\beta$ was initially fixed at 3 .

Unlike the urban site, moisture availability at the reference site at the BoM is unlikely to be constant year-round. Adelaide has a Mediterranean climate with distinct dry and wet seasons, so the use of constant annual values is probably an excessively coarse approximation. The moisture availability index $\alpha$ was modified on a monthly basis, using long-term averages for precipitation and evaporation as an indication of the likely values, as shown in Table V. Moisture availability is almost unrestricted during the cool, wet winter months, so $\alpha$ was assigned a value of 1.0 , corresponding to the maximum value for parks in Table II, or the mid-range for crops with sufficient soil moisture. During the dry summer months, $\alpha$ is assumed to equal about 0.25 , with intermediate values assigned to the spring and autumn periods. Since the BoM meteorological station is surrounded by typical suburban low-rise buildings, $\beta$ was assigned a fixed value of $10 \mathrm{~W} \mathrm{~m}^{-2}$, somewhat more than the recommended value for urban sites, but less than the value of $20 \mathrm{~W} \mathrm{~m}^{-2}$ reported for rural locations.

The effects of short-term wetting of impervious surfaces are modelled by increasing the moisture availability index $\alpha$ of the urban site by (an arbitrarily fixed amount of) 0.1 during rain events, defined as rainfall in excess of $0.5 \mathrm{~mm}$ per hour, and for a period of $1 \mathrm{~h}$ immediately afterwards. The moisture availability index at the reference site is not adjusted, because where surfaces are pervious rainwater does not increase the amount of moisture available for evaporation unless the soil is already at field capacity - a condition reflected in the higher monthly values assigned to this site.

\subsection{Values for the mixing coefficient at the top of the canopy layer}

Having fixed initial (tentative) values for the coefficients incorporated in the parameterisation of the storage flux and of sensible heat production on the basis of published data, the coefficient of turbulent exchange for each of the mixing regimes described in Table I above was determined empirically using the June 2000 data, so as to minimise the error in the predicted air temperature in the urban canyon. Once appropriate values were obtained for each of the mixing regimes (Table VI), they remained unchanged for the remainder of the validation procedure and were used in the simulation of CAT in all other monitoring periods.

\section{MODEL VALIDATION}

The validation of the model is based on comparison of predicted temperatures with observed data assembled in the field experiment. Willmott (1981) noted that use of the correlation coefficient $(r)$ is generally an insufficient test of the predictive ability of models, and recommended that in addition a comparison should be made between the observed and predicted variates' respective means $(\bar{O}, \bar{P})$ and standard deviations $\left(s_{\mathrm{o}}, s_{\mathrm{p}}\right)$; the intercept and slope of a least squares linear regression between the variates; and the errors, described by the root mean squared error (RMSE) and its systematic and unsystematic components. Furthermore, he proposed an index of agreement based on the ratio between the potential error of the sample and the portion of this error left unexplained by the simulated variate.

An obvious difficulty in applying all of the above tests to the predicted and observed temperature records in the current experiment is that there is a high degree of auto-correlation between the variables. Likewise, 
Table IV. Values of $\alpha$ and $\beta$ in the parameterisation for sensible heat flux in different landscapes (Hanna and Chang, 1992)

\begin{tabular}{lcc}
\hline & $\alpha$ & $\beta\left(\mathrm{Wm}^{-2}\right)$ \\
\hline $\begin{array}{l}\text { Dry desert with no rain for months } \\
\text { Arid rural area }\end{array}$ & $0.0-0.2$ & 20 \\
$\begin{array}{l}\text { Crops and field, midsummer during } \\
\text { periods when rain has not fallen for }\end{array}$ & $0.2-0.4$ & 20 \\
several days & & 20 \\
$\begin{array}{l}\text { Urban environments, some parks } \\
\text { Crops, fields or forests with sufficient } \\
\text { soil moisture }\end{array}$ & $0.5-1.0$ & 20 \\
$\begin{array}{l}\text { Large lakes or ocean with land more } \\
\text { than 10 km distant }\end{array}$ & $1.2-1.4$ & 20 \\
\hline
\end{tabular}

Table V. Values of the moisture availability parameter $\alpha$ for urban and reference sites in Adelaide, on a monthly basis. (Long-term averages for rainfall and pan evaporation were obtained from The Australian Bureau of Meteorology, Kent Town station)

\begin{tabular}{lcccccccccccc}
\hline Month & $\mathrm{J}$ & $\mathrm{F}$ & $\mathrm{M}$ & $\mathrm{A}$ & $\mathrm{M}$ & $\mathrm{J}$ & $\mathrm{J}$ & $\mathrm{A}$ & $\mathrm{S}$ & $\mathrm{O}$ & $\mathrm{N}$ & $\mathrm{D}$ \\
\hline$\alpha$ (BoM site) & 0.25 & 0.25 & 0.25 & 0.4 & 0.8 & 1.0 & 1.0 & 0.8 & 0.6 & 0.4 & 0.25 & 0.25 \\
$\alpha$ (Urban site) & 0.25 & 0.25 & 0.25 & 0.25 & 0.25 & 0.25 & 0.25 & 0.25 & 0.25 & 0.25 & 0.25 & 0.25 \\
Mean monthly & 19.6 & 14.1 & 26.2 & 39.5 & 62.6 & 81.6 & 77.8 & 68.1 & 64.3 & 47.8 & 30.3 & 26.5 \\
rainfall (mm) & & & & & & & & & & & & \\
$\begin{array}{l}\text { Mean monthly } \\
\text { evaporation (mm) }\end{array}$ & 220.1 & 187.6 & 151.9 & 90.0 & 58.9 & 42.0 & 46.5 & 65.1 & 90.0 & 133.3 & 171.0 & 201.5 \\
\hline
\end{tabular}

Note: Actual rainfall during the monitoring period was as follows: May $89.8 \mathrm{~mm}$; June $81.2 \mathrm{~mm}$; November $9.0 \mathrm{~mm}$ and March $9.4 \mathrm{~mm}$.

Table VI. Values of the coefficient of turbulent exchange $m$ for different turbulence classes

\begin{tabular}{lc}
\hline Mixing regime & $\begin{array}{c}\text { Mixing coefficient, } \\
m\end{array}$ \\
\hline Negligible mixing & 0.61 \\
Light mixing & 0.76 \\
Moderate mixing & 0.81 \\
Vigorous mixing & 0.92 \\
\hline
\end{tabular}

Willmott's index of agreement may not be a useful test, because the variables are not random. A further test was thus used, based on the Williamson confirmation factor $D$ (Williamson, 1995), which may be summarised as follows:

If the value $v$ of a model input variable can provide a fairly close approximation to the measured parameter $m$, a model may only be considered useful if the estimated value of the parameter in question $e$ is closer to the observed value than this trivial approximation. The expression $C_{\mathrm{s}}=U(m, v)-U(e, m)$ where $U(m, v)$ is Theil's inequality coefficient (a measure of the bias, variance, and covariance of two time series) between the measured value and the trivial variable estimate, and $U(e, m)$ is Theil's inequality coefficient between the estimated value and the measured value of the parameter in question, is an indicator of the magnitude of the error in prediction: The maximum value of the $C_{\mathrm{s}}$ is $U(m, v)$, when $U(e, m)$ is equal to zero, indicating 
perfect correlation between the measured and estimated values. Dividing the confirmation factor $C_{\mathrm{s}}$ by $U(m, v)$ normalises all possible values of this factor, giving a degree of confirmation $D$ having a value between zero and unity.

$$
D=\frac{U(m, v)-U(e, m)}{U(m, v)}
$$

\subsection{Sensitivity analysis}

The sensitivity of model predictions to empirical inputs used in the parameterisation schemes was examined by evaluating the effect on predicted air temperature, expressed by the following statistical measures:

- Changes in the mean error of the predictions are an indication of the absolute magnitude of the effect, as well as its direction, i.e. an increase in the value of the predicted air temperature relative to the observed one, or a decrease.

- Changes in the standard deviation of the error in prediction are an indication of the overall robustness of the model.

- Changes in the Williamson degree of confirmation give an indication of the effect of changes on the quality of model predictions relative to the trivial estimate (in this case, air temperature at the reference site).

Values of the Willmott index of agreement were consistently very high (above 0.95), reflecting the autocorrelation between the temperature records at the different sites, so its value as a measure of the sensitivity of the predictions was limited.

The analysis shows that the mixing coefficients, which are applied to the total sensible heat flux in the final stage of the simulation, have the greatest effect on the accuracy of the predictions. An increase in the value of $m$, for any of the mixing classes, results in a proportional increase in the predicted air temperature, and hence in the difference between the predicted and observed temperatures (also referred to here as the error of the prediction). However, neither the standard deviation nor the Williamson degree of confirmation responds in a similar way. These statistics, which are measures of the quality of the model, show that coefficients $m_{2}, m_{3}$ and $m_{4}$ are close to their optimal value. The value of coefficient $m_{1}$, however, is probably somewhat too high, as indicated by the fact that lower values than the base for the sensitivity analysis result in lower standard deviations of the error and a slightly higher degree of confirmation.

Coefficients $\alpha$ and $\beta$, which are used in the calculation of sensible heat flux (Equation 15), likewise have a substantial effect on the outcome of the simulation. An increase in the value of both $\alpha$ and $\beta$ at the reference site results in a decrease in the predicted temperature at the urban site, and thus a decrease in the error of prediction. A comparable increase in the value of either coefficient at the urban site has the opposite effect: The predicted temperature is higher, and the mean error of prediction greater.

However, since the error is defined simply as the difference between predicted and observed temperatures at the urban site, it is the standard deviation of the error and the Williamson degree of confirmation that give an indication of the overall agreement between them. Both statistics indicate that the initial value of $\alpha$ at the urban site, 0.25 , is approximately correct, while the value of $\alpha$ at the reference site should probably be somewhat lower than the initial value of 1.0 (for the month of June). The sensitivity analysis also suggests that the initial value of $\beta$ at the reference site is probably too low, while its value at the urban site may be a little too high. The best-fit values of these coefficients for the reference and urban sites are probably about 15 and 0 , respectively.

Compared with the values of the coefficients of the sensible heat parameterisation, the values of the coefficients of the OHM model of heat storage have only a minor effect on the result of the prediction of air temperature. There are several reasons for this. First, the storage flux is smaller in magnitude than other components of the heat balance for much of the time, so any error in its calculation has a smaller effect on the final outcome of the simulation. Second, if the area of a particular surface is small in comparison to the total area of the site, as is the case with canyon walls at the reference site, the effect of heat storage at this surface becomes proportionally smaller. Finally, if the two sites incorporate similar materials, e.g. wall surfaces, it is 
only the difference in surface area between them that causes a difference in the storage flux, and the effect of an error in describing heat storage is thus reduced. It is not surprising, therefore, that in a relatively deep street canyon, such as the urban site in Adelaide, heat storage occurs mostly in the walls. This difference is mostly due to coefficient $a_{3}$.

\subsection{Simulation results}

5.2.1. Graphic output. A first indication of the goodness-of-fit of the predictions may be gained by visual inspection of a graphic output of the results. Having used the June data to calibrate the model, observations from other periods were used to evaluate its performance. Figure 5 shows the observed and predicted air temperature at the Chesser Street site for a ten-day period during the month of May 2000, as well as temperature at the BoM site used as the reference for the simulation. The graphic description of daily weather is intended only as a general indication of conditions, and is based mainly on cloud cover, classified as follows: sunny - average cloud cover for the 24-h period - 0-2 tenths; mainly sunny - 2-4 tenths; partly cloudy -4-7 tenths; overcast -7-10 tenths. Days in which total rainfall exceeded $1 \mathrm{~mm}$ are depicted as rainy.

The periods in question were selected because they are characterised by a variety of weather conditions, alternating between dry, mostly sunny days and overcast rainy ones. During these sequences, the temperature difference between the BoM station and the Chesser Street site varied from being negligible to about $5^{\circ}$, providing a rigorous test of the suitability of CAT to predict air temperature in changing environmental conditions. The graphs indicate that the program is capable of reproducing the main features of temperature evolution in the street canyon: The nocturnal heat island that occurred on several days was simulated correctly, albeit with a slight tendency to under-predict its intensity, as were temperatures on cloudy or rainy days.

The difference between observed and predicted values was then plotted against several environmental indicators measured at the reference site and against time of day, to test for any systematic error in the simulation. Figure 6(a) shows that the relationship between the error and the dry bulb temperature of the air appears to be random, implying that there is no bias for either warm or cool weather conditions. Cloud cover (Figure 6(b)) may be interpreted in this context as an overall descriptor of weather conditions: The lack of correlation between error and cloud cover demonstrates that the CAT model is not limited to fair weather, for instance. Figure 6(c) is a test of the assumption that advection may be ignored in the simulation. Since land cover in the vicinity of the test sites is not uniform, advection from particular source areas would have appeared as a bias on the graph. The random distribution of the error with respect to wind direction therefore indicates that for the site in question, at least, advected heat is not a major source of error in the simulation. Figures 6(d) and (e) may be interpreted as a proxy for atmospheric stability, in addition to displaying the relationship between the error and wind speed and global solar radiation, respectively. The only variable that displays what appears to be a non-random relationship with the error in prediction is time of day, shown in

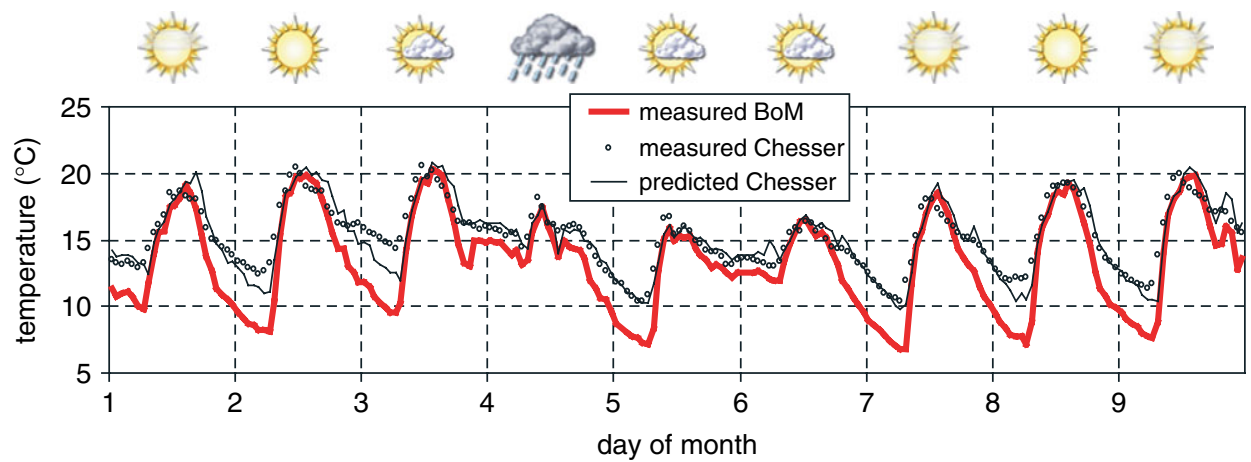

Figure 5. Comparison of predicted air temperature at Chesser Street with observed data for a 9-day period in May 2000. This figure is available in colour online at www.interscience.wiley.com/ijoc 


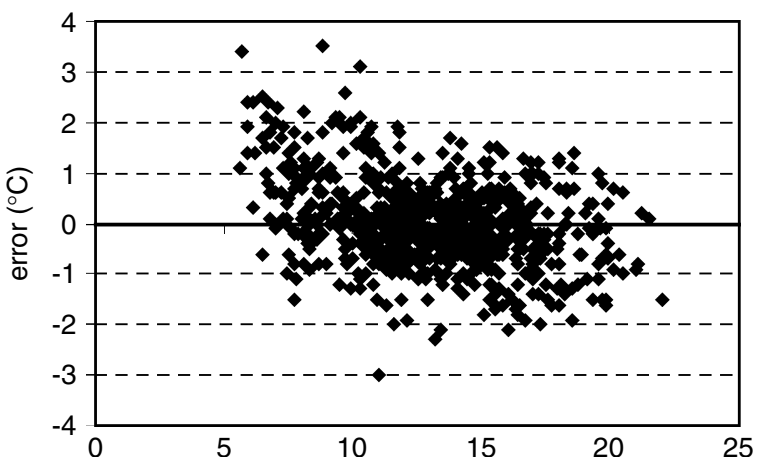

(a)
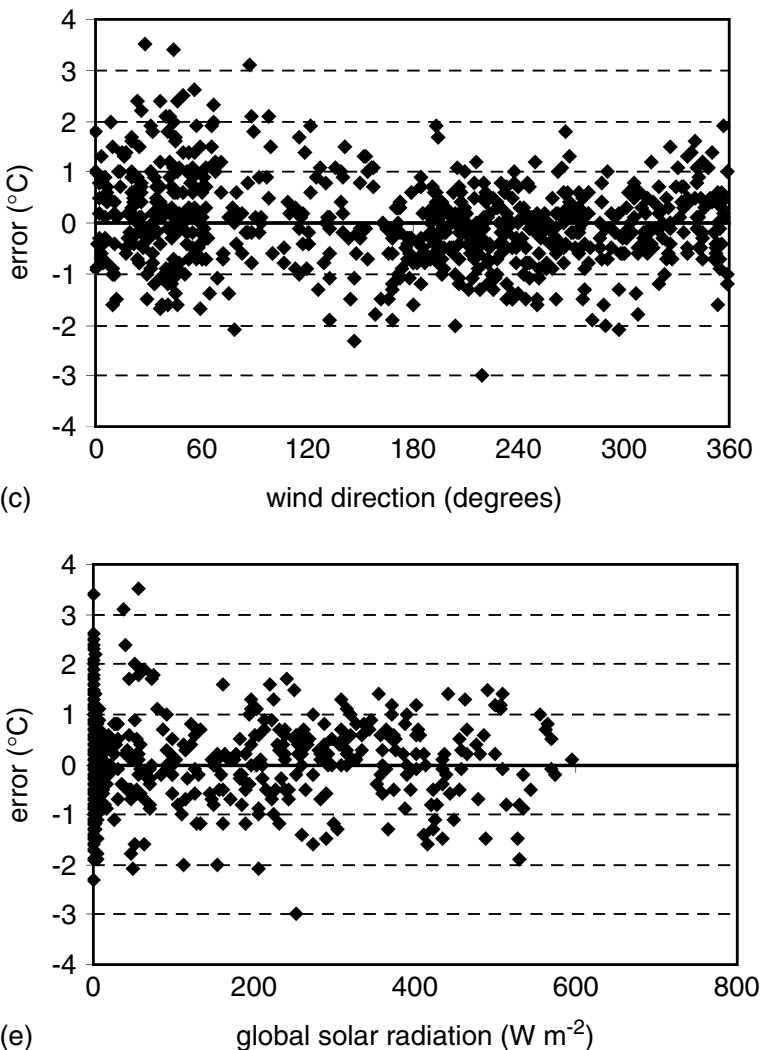

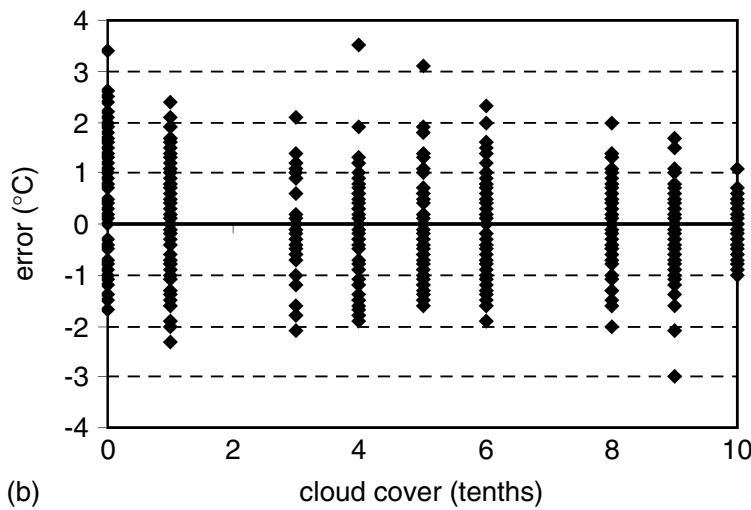

(b)
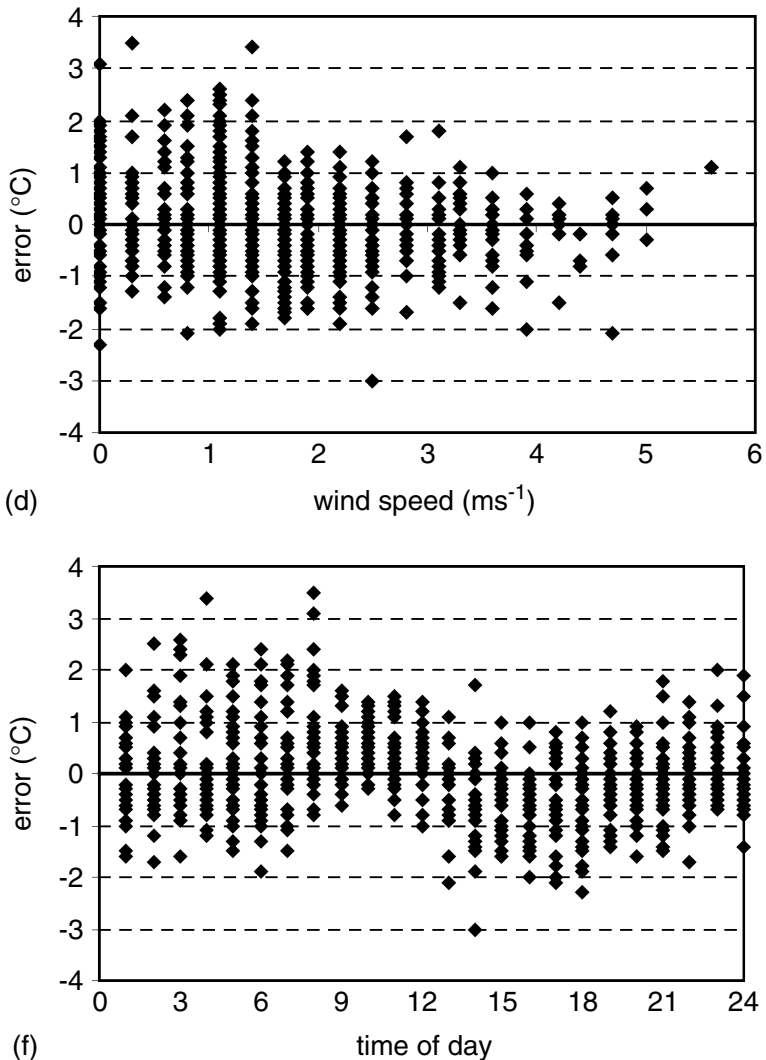

Figure 6. Plot of error in predicted air temperature during May 2000 against (a) air DBT, (b) cloud cover, (c) wind direction, (d) wind speed, (e) global radiation and (f) time of day

Figure 6(f). The relationship is relatively weak, and the lack of correlation with any of the environmental variables does not suggest a specific mechanism to explain this anomaly. It is worth noting in this context that the correlation between time of day and the error in prediction for the months of June and November 2000 and for March 2001 do not display the same pattern. A possible explanation is that the input of anthropogenic heat in the model is insufficiently detailed to account for actual fluxes. Modifying the model to incorporate hourly changes in the magnitude of the anthropogenic flux resulted in a more random distribution of the error with the time of day. However, there were no means of carrying out a continuous audit of the anthropogenic sources of heat in the urban and reference sites during the experiment to confirm that any specific values are 
in fact more representative of anthropogenic heat in the context of the specific test sites than the less detailed estimate used in the model.

5.2.2. Statistical analysis. The quality of the modelled temperature prediction was assessed by comparison of the predicted and observed values of selected descriptive statistics for each month, such as the mean daily temperature (Table VII), and by error analysis and goodness-of-fit tests such as the Willmott index of agreement and the Williamson degree of confirmation (Table VIII). Data were collated for four monthly periods for which complete, uninterrupted time series are available for both the BoM reference site and for the urban street canyon site. In the tables, the figures for the month of June, displayed against a shaded background, reflect the fact that the data for this month were used to calibrate the model. Figures for the other months are, however, a true test of the accuracy of CAT.

Analysis of the simulation results provide a number of insights:

- In all of the monthly periods simulated, the predicted air temperature in the urban canyon is a better approximation of real conditions at the site than the temperature measured at the BoM reference site.

- Both the descriptive statistics and the error analysis show that the predictions for the month of May, which was characterised by meteorological conditions similar to those in the month of June, are better than predictions for November and March, which were extremely dry.

- The comparatively lower values of the Williamson index of confirmation for the months of November and March reflect the fact that during these months the difference between conditions at the reference site and at the urban sites was much smaller than the difference during the months of May and June (Figure 7). Thus,

Table VII. Comparison of predicted and observed monthly temperature data. June 2000 data were used for calibrating the model. (Note: $\mathrm{O}$ - observed, $\mathrm{P}$ - predicted)

\begin{tabular}{|c|c|c|c|c|c|c|c|c|c|c|c|c|}
\hline & \multicolumn{3}{|c|}{ May 2000} & \multicolumn{3}{|c|}{ June 2000} & \multicolumn{3}{|c|}{ November 2000} & \multicolumn{3}{|c|}{ March 2001} \\
\hline & \multirow[t]{2}{*}{ BoM } & \multicolumn{2}{|c|}{ Chesser } & \multirow[t]{2}{*}{ BoM } & \multicolumn{2}{|c|}{ Chesser } & \multirow[t]{2}{*}{ BoM } & \multicolumn{2}{|c|}{ Chesser } & \multirow[t]{2}{*}{ BoM } & \multicolumn{2}{|c|}{ Chesser } \\
\hline & & $\mathrm{O}$ & $\mathrm{P}$ & & $\mathrm{O}$ & $\mathrm{P}$ & & $\mathrm{O}$ & $\mathrm{P}$ & & $\mathrm{O}$ & $\mathrm{P}$ \\
\hline Absolute minimum & 5.60 & 7.30 & 7.28 & 3.40 & 7.64 & 5.21 & 11.60 & 13.40 & 11.70 & 9.30 & 13.03 & 10.46 \\
\hline Mean minimum & 9.05 & 10.49 & 10.15 & 11.03 & 12.15 & 11.56 & 20.09 & 21.08 & 20.38 & 14.26 & 15.71 & 14.91 \\
\hline Average & 13.03 & 14.55 & 14.55 & 11.37 & 12.90 & 12.90 & 21.78 & 22.13 & 22.40 & 19.77 & 20.41 & 20.73 \\
\hline Mean maximum & 17.13 & 17.29 & 17.79 & 15.35 & 15.51 & 16.22 & 27.24 & 26.34 & 26.94 & 25.25 & 24.43 & 25.37 \\
\hline Absolute maximum & 22.00 & 22.00 & 22.28 & 18.80 & 18.84 & 19.46 & 38.90 & 37.80 & 39.01 & 36.30 & 35.74 & 35.61 \\
\hline
\end{tabular}

Table VIII. Statistical evaluation of the predicted air temperature at the urban site. June data (shaded cells) were used to calibrate the model

\begin{tabular}{lcccr}
\hline & May & June & November & March \\
\hline Total number of hours & 744 & 720 & 720 & 744 \\
Mean error & 0.00 & 0.00 & -0.27 & -0.37 \\
Standard deviation of the error & 0.87 & 0.98 & 0.85 & 1.13 \\
Maximum error & 3.40 & 4.67 & 2.94 & 4.14 \\
Minimum error & -3.14 & -2.43 & -3.04 & -4.11 \\
Mean square error (MSE) & 0.761 & 0.969 & 0.789 & 1.416 \\
Systematic MSE & 0.016 & 0.163 & 0.103 & 0.180 \\
Unsystematic MSE & 0.745 & 0.805 & 0.687 & 1.236 \\
Willmott index & 0.974 & 0.956 & 0.993 & 0.988 \\
Theil inequality coefficient & 0.029 & 0.038 & 0.019 & 0.028 \\
Williamson degree of confirmation & 0.583 & 0.564 & 0.328 & 0.339 \\
\hline
\end{tabular}




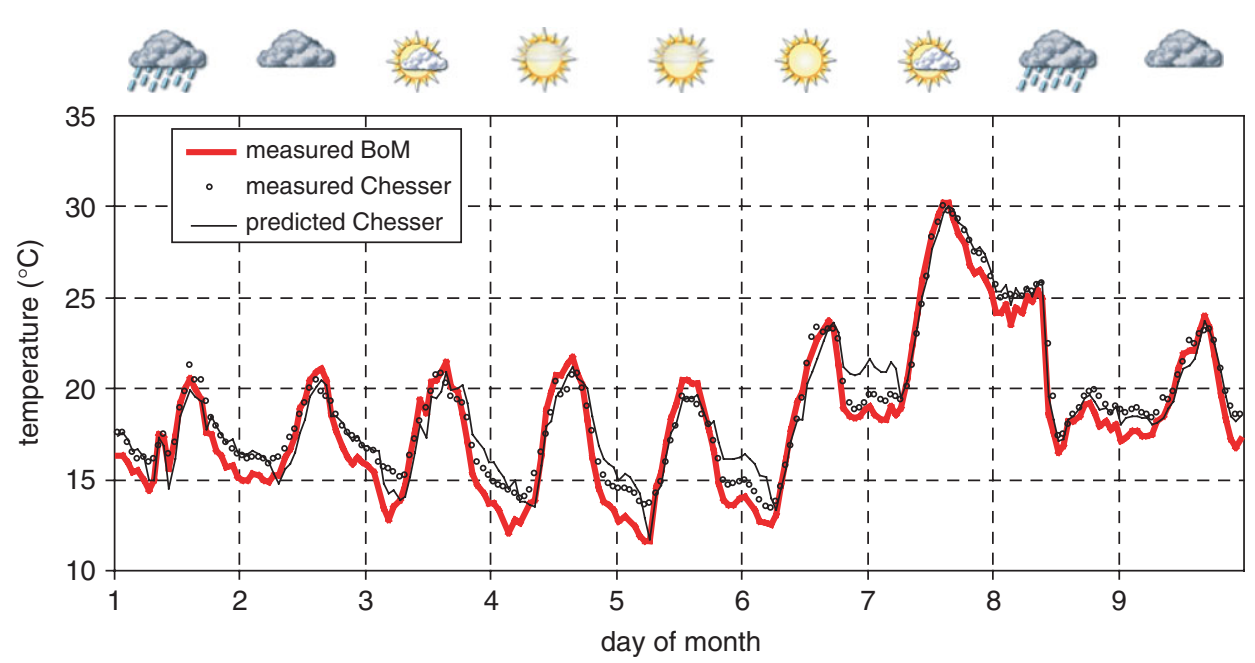

Figure 7. Comparison of predicted air temperature at Chesser Street with observed data for a 9-day period in November 2000. This figure is available in colour online at www.interscience.wiley.com/ijoc

although the standard deviation of the error of prediction in November is very low - only $0.85^{\circ} \mathrm{C}-$ the Williamson degree of confirmation is still only about 0.33 , while a similar standard deviation in May resulted in a degree of confirmation nearly twice as high - about 0.58 .

- The systematic part of the mean square error is very low (in the case of May - negligible), so most of the error is unsystematic. This indicates that there are no substantial elements missing from the model, and that most of the main factors are modelled adequately.

- While the mean monthly temperature is generally predicted quite accurately, the predicted mean monthly minima and maxima both tend to be somewhat higher than observed values.

- While CAT provides predictions of mean monthly temperatures that are much closer to observed values than the default average at the BoM station, and the predicted temperature curve appears to track observed temperatures fairly closely, the model is not yet able to predict isolated incidents with the same degree of accuracy. Thus, the monthly extremes of temperature (high or low) may not be predicted accurately enough for the tool to be used for short periods of time. Its main utility is in providing adjustment to longer time series, such as those used to model temperature or energy consumption in the built environment over extended periods.

\section{3. 'Reverse' simulation}

Prediction of air temperature using the CAT model is carried out in two steps: First, the base temperature is derived by subtracting from the measured air temperature at the reference station a temperature modification resulting from the micro-climatic effects of the site; the micro-climatic modifications resulting from the sitespecific conditions at the urban site are then added to the base temperature, thus obtaining the predicted air temperature. The CAT model does not pose any special requirements with respect to the characteristics of the reference site or the urban site, except for limitations resulting from the capacity of the wind model to predict wind speed near each of the canyon surfaces. The model may therefore be used to model air temperature in an urban street canyon on the basis of reference data at a standard meteorological station - but it should also be able to perform the reverse simulation, and predict air temperature at an exposed site on the basis of urban air temperature. Furthermore, since the base temperature is always calculated as an interim step in the simulation process, and since it is assumed to be spatially homogeneous (within the limits of the relevant area), its value should be the same irrespective of the location and physical properties of the reference site.

These assumptions were tested using data for the month of May 2000. The simulation was carried out twice: First, the air temperature at the Chesser Street urban site was predicted on the basis of measured data 
from the reference site at the BoM station at Kent Town (the 'forward' simulation). Then measured data from the Chesser Street site were used to predict temperature at the Kent Town BoM station (the 'reverse' simulation). The base temperature was therefore calculated independently twice, providing a direct test of the assumptions regarding independence of location and spatial homogeneity.

Figure 8(a) shows two time series representing the interim 'base temperature' for a sample period of 10 days. The lines are clearly similar; a test of linear correlation on the basis of data for the entire month gave a line of best fit through the origin with a slope of $0.97\left(r^{2}=0.90\right)$. The close correlation indicates that there are no major unexplained factors missing from the model. Furthermore, since both calculations of the base temperature are based on real site data, measurement errors are responsible for at least part of the variance.

Further support for the underlying concept of the model, which relates screen level temperatures and surface modifications to a spatially homogeneous mixed layer above the buildings of the city, is found in the complete results of the 'reverse' simulation, in which air temperature at the BoM station was predicted on the basis of urban air temperature (Figure 8(b) and Table IX). The impression given by visual inspection of the graph is supported by the error statistics, namely that the reverse simulation is as accurate as the forward one.

\section{DISCUSSION}

The CAT model assumes that the air temperature at some reference height above the canopy layer is approximately uniform over the area in which both the reference station and the urban canyon are located. If there are significant variations in the surface energy balance in the area, this implies substantial mixing of the air.

Schmid et al. (1991) found that energy fluxes over what appeared to be a homogeneous suburban residential area varied by up to $40 \%$ within horizontal scales of only $100-1000 \mathrm{~m}$. The present study supports these findings. However, although such horizontal variations of vertical turbulent energy fluxes in the presence of a

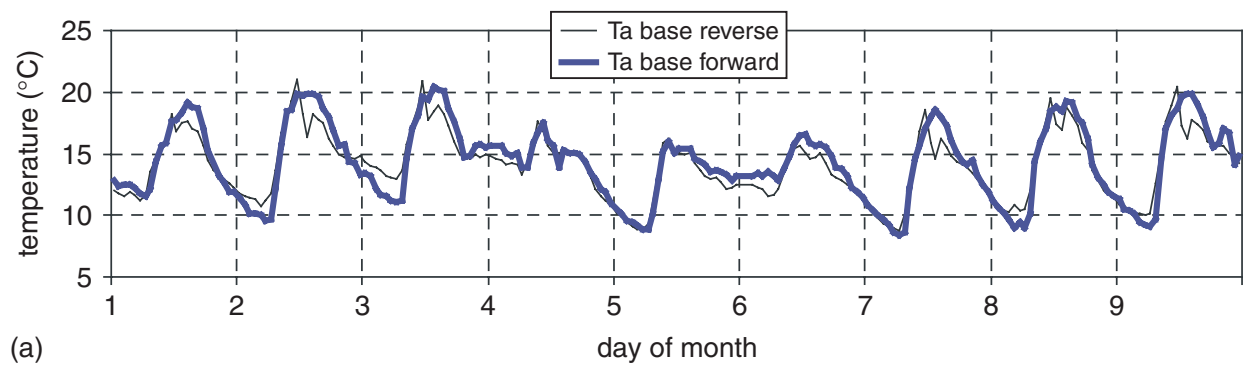

(a)

day of month

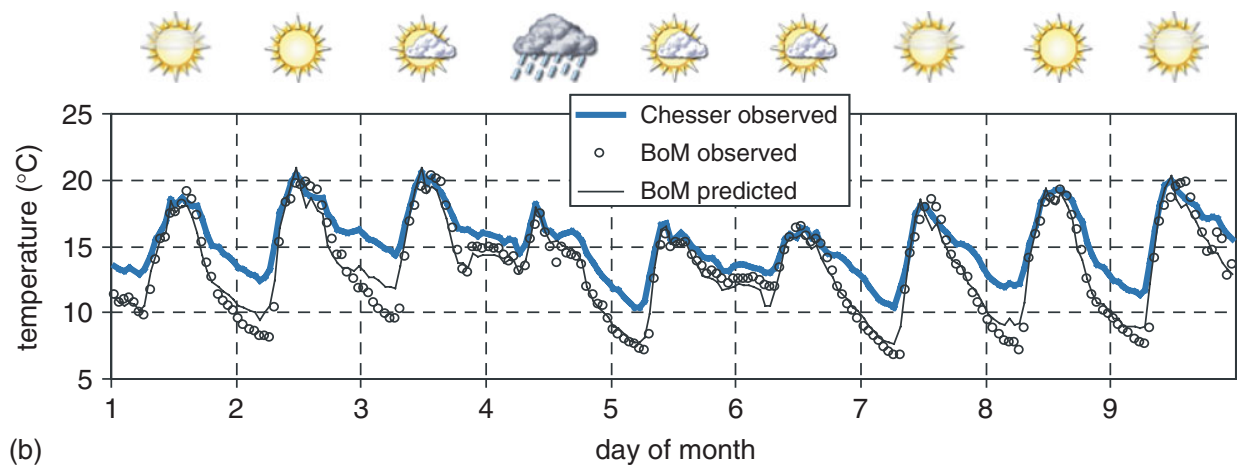

Figure 8. Sample results of the 'reverse simulation' for the first 9 days of May 2000: (a) Base temperature calculated by means of the 'forward' and 'reverse' simulations, and (b) Air temperature at the BoM reference site predicted from measured air temperature at Chesser Street. This figure is available in colour online at www.interscience.wiley.com/ijoc 
Table IX. Statistics of 'reverse' simulation for prediction of air temperature at BoM site from measured urban air temperature

\begin{tabular}{lc}
\hline & May \\
\hline Total number of hours & 744 \\
Mean error & 0.00 \\
Standard deviation of the error & 0.87 \\
Maximum error & 3.40 \\
Minimum error & -3.14 \\
Mean square error (MSE) & 0.761 \\
Systematic MSE & 0.128 \\
Unsystematic MSE & 0.633 \\
Willmott index & 0.981 \\
Theil inequality coefficient & 0.032 \\
Williamson degree of confirmation & 0.54 \\
\hline
\end{tabular}

mean flow must induce advection, this study found little evidence of an effect of what Schmid et al. referred to as 'micro-advection' on air temperature in the locations monitored. This is in spite of the fact that the study area included several, very different urban landscapes.

CAT is clearly applicable where building density, topology and ground cover in the source area for energy fluxes are approximately homogeneous. However, it may not be applicable in its present form where this condition cannot be met, e.g. where there are substantial differences in the meso-scale properties of the sites such as topography, elevation, distance from a large body of water etc. Having made this qualification, it should be noted that measurements made in the urban sites as part of this research nevertheless suggest that the presence of urban parks or large variations in building height and street sections in the source area of the airflow advected to them may have only a minor effect on canyon air temperature. There is need for further field research to establish the magnitude of the effect on canyon air temperature of such meso-scale features, taking into account their distance from the street in question, the direction of the wind and the intensity of the fluxes.

Calculation of net radiant flux at the surface $\left(Q^{*}\right)$ incorporates the sol-air temperature as an approximation of the real surface temperature. This has been shown to result in negligible errors in the case of exposed soil surfaces, but might result in larger errors if the methodology is applied to other types of surfaces:

- Vegetated surfaces, whose temperature is regulated by evapotranspiration and sometimes by radiant and convective exchange with sub-canopy surfaces.

- Thin materials not coupled to a substantial thermal mass, which may experience very large and rapid changes in temperature in response to changes in radiant flux.

The CAT model uses empirical correlations to estimate the convective heat transfer coefficient $h_{\mathrm{c}}$ from wind speed near the surface (Equation 10). The value of this coefficient is then incorporated in the calculation of the sol-air temperature of each of the canyon surfaces and in the overall heat transfer from the canyon system to the roughness sublayer. It would therefore appear that accurate determination of the coefficient has a direct bearing on the quality of the model predictions. However, the nature of the correlations, which are in the form of a sum of a constant factor and a wind-related one, is such that the value of $h_{\mathrm{c}}$ is relatively insensitive to changes in the wind at low speeds, and more so at high speeds. The magnitude of the absolute error in prediction resulting from an inaccurate estimate of the convective heat transfer coefficient is therefore in practice fairly small: In windy weather, air temperature in the urban street canyon is likely to be very similar to the temperature of the surroundings, as reflected in the high value of the mixing ratio $m$ for turbulent conditions. In relatively calm weather, the absolute error in the estimate of $h_{\mathrm{c}}$ is likely to be small, resulting in a proportionately small error in the prediction of CAT. Nevertheless, improving the accuracy 
of the estimate for $h_{\mathrm{c}}$ in urban configurations where canyon air flow is not characterised by a simple rotor vortex - either because the canyon is too shallow (resulting in isolated roughness flow) or because it is very deep (resulting in very weak coupling of street-level wind with air above the canyon) - remains a priority for future development of the model.

Assessment of the sensible heat flux is sensitive to the value of the coefficient $\alpha$ in Equation 15. This coefficient, which describes the availability of moisture in different environments, may range in value between zero in hyper-arid locations to about 1.4 over oceans (Grimmond and Oke, 2002). In most urban sites, it is likely to be in the range $0.2-1.0$, but a more accurate determination may require calibration of the CAT model to a variety of locations on the basis of experimental data from on-site monitoring. Until such data are available, calibration may be carried out to fit predictions to data from the reference site in meteorological conditions that are known to result in negligible urban effects, such as windy, overcast weather. This procedure may only be carried out if the contribution of anthropogenic heat to temperature differences between the locations is small.

CAT uses an empirical correlation between the sol-air temperature of an exposed reference surface and a coefficient of mixing between the urban canopy and the mixed layer above roof height. Accuracy of model predictions is sensitive to values of this coefficient, so further examination of this procedure and validation against observed data in a variety of environmental conditions are required before the model can be applied with confidence in climates or urban morphologies that are very different from Adelaide.

\section{CONCLUSIONS}

The CAT model demonstrates that a relatively simple analytical model based on established parameterisations of the urban canyon heat fluxes can provide consistent estimates of air temperature that are a substantial improvement over the trivial case of using unprocessed time-series data from a reference weather station. In addition to a rudimentary description of the two sites, it requires only inputs measured at standard weather stations, yet it is capable of predicting accurately the evolution of air temperature in all weather conditions for extended periods. It simulates the effects of urban geometry on radiant exchange; the effect of moisture availability on latent heat flux; energy stored in the ground and in building surfaces; air flow in the street based on wind above roof height; and the sensible heat flux from individual surfaces and from the street canyon as a whole.

The model was validated using field data recorded over a period of almost a year in several locations in Adelaide. Comparison of observed and predicted air temperature using standard descriptive statistics such as means, maxima and minima, as well as more advanced analysis of errors in prediction using techniques such as the Williamson confirmation factor, demonstrates that once calibrated for specific local conditions the CAT model is capable of providing time series of air temperature in an urban street canyon that are significantly closer to real temperature than measurements made at a standard meteorological station in the metropolitan area.

The model in its current form is still limited, especially with respect to the types of urban morphology it may be applied to. It has also not been tested against field data from locations other than Adelaide, which may have substantially different micro-climates. It therefore remains to be seen whether the empirical calibration factors deduced from the Adelaide data may be applied elsewhere. If these restrictions can be overcome, the CAT computer model is seen as having several practical applications:

- Evaluation of the micro-climatic effects of proposed planning regulations concerning land use and building density in new or existing urban development;

- Evaluation of changes to the micro-climatic conditions at specific urban locations as a result of proposed changes such as new construction;

- Use as a research tool for examining various urban configurations in terms of their effect on pedestrians and on consumption of energy in buildings.

- Provision of data representing realistic site-specific meteorological conditions that may then be input to building thermal simulation software to produce more accurate modelling of energy use. 


\section{ACKNOWLEDGEMENTS}

The authors would like to thank Mr MacLachlan and Mr Tormet for allowing meteorological equipment to be installed in their buildings at Chesser and French Streets for the duration of the experiment; the Adelaide City Nursery, which provided a site for the reference station and the City Council of Adelaide for their support of the project. The Australian Bureau of Meteorology provided meteorological data for Kent Town.

\section{REFERENCES}

Anandakumar K. 1990. A study of the partition of net radiation into heat fluxes on a dry asphalt surface. Atmospheric Environment. Arnfield J. 1982. An approach to the estimation of the surface radiative properties and radiation budgets of cities. Physical Geography 3(2): $97-122$.

Arnfield J. 1990. Canyon geometry, the urban fabric and nocturnal cooling: a simulation approach. Physical Geography 11(3): 220-239. Arnfield J. 2000. A simple model of urban canyon energy budget and its validation. Physical Geography 21(4): $305-326$.

Arnfield JA, Grimmond CSB. 1998. An urban canyon energy budget model and its application to urban storage heat flux modeling. Energy and Buildings 27: 61-68.

Arnfield J, Herbert JM, Johnson GT. 1988. A numerical simulation investigation of urban canyon energy budget variations. Second Urban Environment Symposium. American Meteorological Society: Albuquerque, Ne Mexico.

Asaeada T, Ca V. 1993. The subsurface transport of heat and moisture and its effect on the environment: A numerical model. Boundary Layer Meteorology 65: 159-179.

ASHRAE. 1989. ASHRAE Handbook-Fundamentals. American Society of Heating, Refrigerating and Air Conditioning Engineers, Inc: Atlanta, Georgia, USA.

Bornstein RD. 1984. Urban climate models: nature, limitations and applications. Urban Climatology and its Applications with Special Regard to Tropical Areas. World Meteorological Organization: Geneva, Switzerland, Mexico DF.

Bottema M. 1997. Urban roughness modeling in relation to pollutant dispersion. Atmospheric Environment 31(18): 3059-3075.

Bruse M, Fleer H. 1998. Simulating surface-plant-air interactions inside urban environments with a three dimensional numerical model. Environmental Modelling and Software 13: 373-384.

Brutsaert W. 1982. Evaporation into the Atmosphere. Kluwer Academic Publishers: Dordrecht, Boston, MA, London.

Camuffo D, Bernardi A. 1982. An observational study of heat fluxes and their relationships with net radiation. Boundary-Layer Meteorology 23: 359-368.

Chan A, So E, Samad S. 2001. Strategic guidelines for street canyon geometry to achieve sustainable street air quality. Atmospheric Environment 35: 5681-5691.

Chan A, Au W, So E. 2003. Strategic guidelines for street canyon geometry to achieve sustainable street air quality-part II: multiple canopies and canyons. Atmospheric Environment 37: 2761-2772.

Clarke JA. 1993. Assessing building performance by simulation. Building and Environment 28(4): 419-428.

De Bruin H, Holtslag A. 1982. A simple parameterization of the surface fluxes of sensible and latent heat during daytime compared with the Penman-Monteith concept. Journal of Applied Meteorology 21: 1610-1621.

Dimoudi A, Nikolopoulou M. 2003. Vegetation in the urban environment: microclimatic analysis and benefits. Energy and Buildings 35(1): 69-76.

Doll D, Ching J, Kaneshiro J. 1985. Parameterisation of subsurface heating for soil and concrete using net radiation data. Boundary Layer Meteorology 32: 351-372.

Elnahas MM. 1996. Energy saving through urban design-a microclimatic approach. PhD thesis, Department of Architecture, The University of Adelaide, Adelaide, Australia, 170.

Elnahas MM, Williamson TJ. 1997. An improvement of the CTTC model for predicting urban air temperatures. Energy and Buildings 25: $41-49$.

Erell E, Williamson T. 2006. Observations on the nature of the urban canopy layer heat island in a mid-latitude city. International Journal of Climatology (submitted for publication).

Erell E, Leal V, Maldonado E. 2005. Measurement of air temperature in the presence of a large radiant flux: an assessment of passively ventilated thermometer screens. Boundary Layer Meteorolgy 114: 205-231.

Fuchs M, Hadas A. 1972. The heat flux density in a non-homogeneous bare loessial soil. Boundary Layer Meteorology 3: 191-200.

Grimmond CSB, Oke TR. 1999a. Aerodynamic properties of urban areas derived from analysis of surface form. Journal of Applied Meteorology 38: 1262-1292.

Grimmond CSB, Oke TR. 1999b. Heat storage in urban areas: Local-scale observations and evaluation of a simple model. Journal of Applied Meteorology 38: 922-940.

Grimmond CSB, Oke TR. 2002. Turbulent heat fluxes in urban areas: observations and a Local-scale Urban Meteorological Parameterization Scheme (LUMPS). Journal of Applied Meteorology 41: 792-810.

Grimmond CS, Cleugh HA, Oke TR. 1991. An objective heat storage model and its comparison with other schemes. Atmospheric Environment 25B: $311-326$.

Grimmond CSB, King TS, Roth M, Oke TR. 1998. Aerodynamic roughness of urban areas derived from wind observations. BoundaryLayer Meteorology 89: 1-24.

Hagishima A, Tanimoto J. 2003. Field measurements for estimating the convective heat transfer coefficient at building surfaces. Building and Environment 38: 873-881.

Hanna S, Chang J. 1992. Boundary-layer parameterizations for applied dispersion modeling over urban areas. Boundary-Layer Meteorology 58: 229-259.

Hotchkiss RS, Harlow FH. 1973. Air pollution transport in street canyons, EPA-R4-73-029, 117.

Hunter LJ, Watson ID, Johnson GT. 1990, 1991. Modeling air flow regimes in urban canyons. Energy and Buildings 15-16: 315-324. 
Kastner-Klein P, Plate EJ. 1999. Wind-tunnel study of concentration fields in street canyons. Atmospheric Environment 33: $3973-3979$.

Macdonald RW. 2000. Modelling the mean velocity profile in the urban canopy layer. Boundary-Layer Meteorology 97: 25-45.

Martilli A, Clappier A, Rotach MW. 2002. An urban surface exchange parameterization for mesoscale models. Boundary-Layer Meteorology 104: 261-304.

Martin M. 1989. Radiative cooling. In Passive Cooling, Cook J (ed.). MIT Press: Cambridge, MA, 593.

Masson V. 2000. A Physically-based scheme for the urban energy budget in atmospheric models. Boundary-Layer Meteorology 94: 357-397.

McCaughey JH. 1985. Energy balance storage terms in a mature mixed forest at Petawawa Ontario - a case study. Boundary Layer Meteorology 31: 89-101.

Mills G. 1999. Urban climatology and urban design. 15th International Congress of Biometeorology and International Conference on Urban Climatology. Macquarie University: Sydney, Australia.

Nakamura Y, Oke TR. 1988. Wind, temperature and stability conditions in an east-west oriented urban canyon. Atmospheric Environment 22(12): 2691-2700.

Narita K, Sekine T, Tokuoka T. 1984. Thermal properties of urban surface materials - a study on heat balance at asphalt pavement. Geographical Review of Japan 57A: 639-651.

Novak M. 1981. The moisture and thermal regimes of a bare soil in the Lower Fraser Valley during spring. PhD Thesis, The University of British Columbia, Vancouver.

Nunez M, Oke TR. 1977. The energy balance of an urban canyon. Journal of Applied Meteorology 16: 11-19.

Oke TR. 1987. Boundary Layer Climates. Methuen: London, New York.

Rao KR, Ballantyne ER. 1970. Some investigations on the sol-air temperature concept, Division of Building Research Technical Paper No. 27, 9, CSIRO: Melbourne, Australia.

Sailor D, Lu L. 2004. A top-down methodology for developing diurnal and seasonal anthropogenic heating profiles for urban areas. Atmospheric Environment 38: 2737-2748.

Sakakibara Y. 1996. A numerical study of the effect of urban geometry upon the surface energy budget. Atmospheric Environment 30(3): 487-496.

Schmid HP, Cleugh HA, Grimmond SB, Oke TR. 1991. Spatial variability of energy fluxes in suburban terrain. Boundary-Layer Meteorolgy 54: 249-276.

Souch C, Grimmond CSB, Wolfe C. 1998. Evaporation rates for wetlands with different disturbance histories: Indiana Dunes National Lakeshore. Wetlands 18: 216-229.

Swaid H. 1993. Urban climate effects of artificial heat sources and ground shadowing by buildings. International Journal of Climatology 13: $797-812$.

Swaid H, Hoffman M. 1990a. Thermal effects of artificial heat sources and shaded ground areas in the urban canopy layer. Energy and Buildings 15: 253-261.

Swaid H, Hoffman ME. 1990b. Climatic impacts of urban design features for high and mid-latitude cities. Energy and Buildings 14: $325-336$.

Swaid H, Hoffman ME. 1990c. Prediction of urban air temperature variations using the analytical CTTC model. Energy and Buildings 14: $313-324$.

Taha HG. 1978. An urban Micro-Climate Model for Site-Specific Building Energy Simulation: Boundary Layers, Urban Canyon and Building Conditions. Department of Architecture, University of California: Berkeley, CA; 135.

Takahashi K, Yoshida H, Tanaka Y, Aotake N, Wang F. 2004. Measurement of thermal environment in Kyoto city and its prediction by CFD simulation. Energy and Buildings 36: 771-779.

Terjung WH, O'Rourke PA. 1980a. Influences of physical structures on urban energy budgets. Boundary-Layer Meteorology 19: 421-439.

Terjung WH, O'Rourke PA. 1980b. Simulating the causal elements urban heat islands. Boundary-Layer Meteorology 19: $93-118$.

Verseghy DL, Munro DS. 1989. Sensitivity studies on the calculation of the radiation balance of urban surfaces: I. Shortwave radiation. Boundary-Layer Meteorology 46: 309-331.

Wieringa J. 1993. representative roughness parameters for homogeneous terrain. Boundary-Layer Meteorology 63: 323 -363.

Williamson TJ. 1995. A confirmation technique for thermal performance simulation models. Building Simulation '95. IBPSA: Madison, WI.

Willmott CJ. 1981. On the validation of models. Physical Geography 2(2): 184-194.

Xie X, Huang Z, Wang J, Xie Z. 2005. The impact of solar radiation and street layout on pollutant dispersion in street canyons. Building and Environment 40: 201-212.

Yamartino RJ, Wiegand G. 1986. Development and evaluation of simple models for the flow, turbulence and pollutant concentration fields within an urban street canyon. Atmospheric Environment 20: 2137-2156. 